\title{
Insight into Mindfulness and its Practices in Psychology
}

\author{
Malavika S. P. ${ }^{1}$ and Subha Sachithanand ${ }^{2 *}$ \\ ${ }^{1}$ Department of Psychology, Government College for Women, University of Kerala, Kerala, India \\ and ${ }^{2}$ Department $O$ P Psychology, Mahatma Gandhi College, University of Kerala, Kerala, India
}

Email of corresponding author: subhasachithanand@gmail.com

\begin{abstract}
Mindfulness is the ability to focus on present moment, becoming aware of one's thoughts, feelings without judgment. It has been integrated into various therapeutic interventions. Hence mindfulness and its practices are of utmost relevant in current scenario. Inculcating it into our lifestyle and practicing it regularly helps to restore our energy and rejuvenates our both mental and physical health. Mindfulness practices enables us to deal effectively and cope with stress that we face in our daily life, by encouraging us to stay optimistic and mindful. It shifts the way we perceive our life and world. Being mindful is not so easy but it isn't impossible. Its application and benefits are not only limited to ourselves but it extends its prosperity to the people connected to us, the institutions related to us, our family, our society and so on. This article will help you to gain insight into different aspects of mindfulness which includes its history, physiological aspects, techniques used, how it contributes to personal growth and so on. Therefore, this article is written with the intention to throw some light into the importance of practicing mindfulness in your daily life.
\end{abstract}

Keywords: Self Nature; Judge Mental; Enlightment; Therapy; Stress; Well Being.

\section{INTRODUCTION}

According to APA mindfulness refers to a moment to moment awareness of one's experience without judgment. In this sense, mindfulness is a state and not a trait. While it might be promoted by activities, such as meditation, it is not equivalent to or synonymous with them rather meditation is a practice that aids us to be mindful. Whereas another definition given by Jon Kabat Zinn says mindfulness is the awareness that arises from paying attention on purpose, in the present moment and non - judgmentally. It is actually a state of being when our body and mind are at same place and at same time i. e a state of physical and mental presence. The ability to pay attention in the moment with flexibility, openness and curiosity. It is a secular practice. It could be said as simply acknowledging our thoughts feelings without judging it. Mindfulness practice isn't just planned to create here and now awareness and calm, yet in addition to encourage profound progression. Particularly, mindfulness suggests recognition of the non-self nature of the individual and accordingly the planet and of the transient nature of presence. It supports the profound, genuine and ever inquisitive experience with others, regardless of whether human, ecological or psychological, in this way encouraging a procedure of association and trust building which is itself mending and transformational. When we are mindful it creates an attitude of curiosity within us which in turn allows us to devise newer and healthiest ways of responding to challenges in life. It transforms how we relate to events and experiences. These are seen as conceivably effective antidote against most of the regular forms of psychological distress like rumination, anxiety, worry, fear, temper etc.

The elements or the three important characteristics of mindfulness are intention, attention and attitude. Intention to cultivate awareness, attention to what is occurring in the present moment and finally attitude which must be non judgmental, curious and kind. Practicing of mindfulness could dwindle the negative thoughts and thereby promote better quality of life. Attention is one of the key components of mindfulness practice which enhances the capability to sustain non judgmental awareness of one's thinking patterns, emotions and sensory perceptions. To be specific mindfulness cornerstones or supports recognition of automatic thinking patterns. Some of its benefits includes decreased stress response, increased capacity for compassion, boosts immune system activity and ability to relax, enhances ability to regulate emotions, improvements in chronic pain levels, anxiety and depression symptoms, enable to experience moments with great clarity and objectivity. Jon Kabat Zinn in one of his books titled FULL CATASTROPHE LIVING he introduced seven attitudes of mindfulness which are Non-Judging: Noticing when you're being judgmental of yourself and others, Patience: 
Letting things unfold in their own time without rushing ,Beginner's Mind: Being receptive to new possibilities and realizing you don't need to know all of the answers ,Trust: Trusting in yourself and taking responsibility for your actions, NonStriving: Not forcing certain results to happen and letting things happen in their own time, Acceptance: Accepting things as they are in the moment without denying or trying to change things , Letting Go: Being willing to let go of the things, people, or ideas that prevent you from living in the moment. (Beard,M. 2017).

\section{EMERGENCE OF MINDFULNESS AND ITS INTEGRATION WITH PSYCHOLOGY}

Mindfulness seems to have its roots in ancient eastern, primarily in Buddhist traditions. Hinduism is tied to mindfulness through yoga and meditation, but it was popularized in the West by those who learned about mindfulness through Buddhism. Our own is a profound custom of contemplation and meditation. Buddhist used the term Sati which was later translated into English as mindfulness by Thomas William Rhys. According to Buddhists Sati plays a significant role in propagation of inner mind and insight meditation (Vipasana). Sati plays a substantial position in teachings of Buddhists meditation in which it is insisted that correct or right mindfulness is the crucial element in the road to liberation and eventual enlightment. Buddhism aims at enlightenment and Mindfulness is considered as the path towards enlightenment. Sati is giving attention to what is salient in the present moment. The Satipatthana Sutta (The Discourse on the Establishing of Mindfulness) and the subsequently developed Mahasattipatthana Sutta (the Great Discourse on the Establishing of Mindfulness) are two of the most revered and widely studied discourses in the Pali Canon of Theravada Buddhism which serve as the basis for contemporary Vipassana meditation. These Suttas strain the practice of sati (mindfulness) "for the purification of beings, for the overcoming of sorrow and lamentation, for the extinguishing of suffering and grief, for walking on the course of truth, for the belief of nibbana. "As per the
Satipatthana Sutta there are 4 types of mindfulness they are Kayanupassana (Mindfulness of body), Vedananupassana (Mindfulness of feeling), Cittanupassana (Mindfulness of Mind) and Dhammanupassana (Mindfulness of mental phenomena).

Though mindfulness had its earlier roots in East later its popularity was spread to west. The amalgamation of mindfulness into Western medicine and Psychology can be traced back to the expansion of Zen Buddhism in America. In the early 1960's the enthusiasm in the use of meditative techniques in psychotherapy began to flourish among clinicians especially psychoanalysts, it was during the late 1970's mindfulness meditation began to be studied as an intervention to enhance psychological well being. The utilization of mindfulness meditation as a form of behavioral intervention for clinical problems began with work of Dr. Jon Kabat Zinn who used mindfulness meditation (after learning Buddhism under several teachers) in treating patients with chronic pain, now known as MBSR (mindfulness based stress reduction). Dr. Jon Kabat Zinn's contribution paved the way for the expansion and burgeoning of mindfulness in the west. Kabat Zinn and associates have been to a great extent accountable for transforming the original spiritual notion (training of mind to alleviate suffering in ourselves and other) into a powerful and ubiquitous therapeutic tool based on the forms of meditation and mindful practices. Dr. Jon Kabat-Zinn, originator of the Mindfulness Based Stress Reduction (MBSR) program at the University of Massachusetts Medical Center depicts mindfulness as the awareness that takes place through attending present moment from a non judgmental point of view. He devised this 8 week program as a way of helping people to deal with situations ranging from general dissatisfaction that we all go through at some level or another to chronic bodily pain. He sees it as a process of unfolding present moment. There are various therapies incorporating mindfulness which are much of the time utilized by professionals includes Mindfulness-based Stress Reduction (MBSR), Mindfulness-based Cognitive Therapy (MBCT) for depression, Mindfulnessbased Relapse Prevention (MBRP), Acceptance Commitment Therapy (ACT), and Dialectical Behavior Therapy (DBT). 


\section{PHYSIOLOGICAL ASPECTS}

A lot of researches conducted indicates that mindfulness is associated with significant changes in brain structure. The FMRI (functional magnetic resonance imaging) studies in this area indicates that mindfulness is associated with neural mechanisms involving multiple brain regions. While in the most of the studies it has been shown that frontal region has a role, whereas there has been robust evidence for medial frontal regions including anterior cingulated cortex. Perhaps there is very strong evidence that anterior and posterior cortical midline structures (CMS) play a key role in the mechanisms of mindfulness in addition to there is also involvement of amygdala and insula. Mindfulness training seems to modify neural processes in three attention networks (the alerting, orienting and executive, are thought to play specific roles in the attention process) which in turn contributes to improved general and interoceptive attention. Basically there are two types of thoughts controlled and automatic, let's focus onto automatic thoughts. Automatic thoughts are originated unconsciously and it's not so easy to prevent as it is involuntary. Objective awareness of automatic thoughts is implied to be a fundamental mechanism by which mindfulness reduces symptoms of depression, anxiety and stress. Objective awareness permits one to interpret thoughts as "just thoughts" and prevents experiencing irrational negative thinking as fact. Researches have shown significant evidence mindfulness impacts DMN (default mode network, is a large-scale brain network of interacting brain regions known to have activity highly correlated with each other and distinct from other networks in the brain) neural processes, alteration of this network plays a key role in objectification of the experience of automatic thoughts.

\section{TECHNIQUES IN MINDFULNESS}

Body scan meditation: usually done lying down, but you can use any posture you like. This meditation involves becoming aware of your bodily sensations in a mindful way, step by step. You also begin to discover how easily your attention wanders off to other thoughts and how to be kind to yourself rather than self-critical when this happens.

Movement Meditation: Usually yoga, t'ai chi, qi gong or another physical mind-body exercise. This type of meditation involves focusing on your bodily sensations, breathing and mindfully watching and perhaps letting go of whatever thoughts and emotions arise as you practice. Slow walking meditation is another possibility that's sometimes used.

Breathing Space Meditation: A short, roughly three-minute, meditation. Do this practice a few times a day and whenever you experience a highly stressful situation or difficult emotion. The idea is to create a mindful awareness of your experience instead of avoiding it. This approach has been shown scientifically to be much more effective than avoidance.

Expanding Awareness Meditation: Usually called sitting meditation, but it can be practiced in any position. The meditation involves focusing, often in this order, on your breath, body, sounds, thoughts and feelings, and finally developing an open awareness where you're choicelessly aware of whatever is most predominant in your consciousness. The expanding awareness meditation can be divided into separate meditations, each powerful and transformative in themselves:

- Mindfulness of breath meditation: Focusing your attention on the feeling of your in-breath and out-breath. Each time your mind wanders, bring your attention back non-judgmentally.

- Mindfulness of body meditation: Feeling the physical sensation in your body from moment to moment. You can also practise this together with the awareness of breathing.

- Mindfulness of sounds meditation: Being aware of sounds as they arise and pass away. If no ambient sounds exist, you can simply listen to the silence and notice what effect doing so has for you.

- Mindfulness of thoughts meditation: Being aware of your thoughts arising in your mind and passing away and having a sense of distance between yourself and your thoughts. You allow the thoughts to come and go as they please, without judging or attaching to them. 
- Mindfulness of feelings meditation: Noticing whatever feelings arise for you. In particular, you notice where you feel the emotion in your body and bring a quality of acceptance and curiosity to your emotions.

- Open awareness meditation: Sometimes called choice less awareness, because you become aware of whatever's most predominant in your awareness without choosing. You may be aware of any of the above meditation experiences as well.

\section{OTHER EFFECTIVE THERAPIES THAT USE MINDFULNESS}

Mindfulness Based Stress Reduction program It is a meditation program evolved by Jon Kabat Zinn in 1979 by assimilating Buddhists meditation with contemporary clinical and psychological practices. It is an intensively structured training program aimed at easing patients suffering from chronic pain, help them in adapting to mental illness by administering a systematic training in mindfulness meditation. It is a comprehensive and patient centered approach which is a mode of teaching that lets patients know how to live their life fully even going through chronic hardships. The vital aspect of MBSR involves training in mindfulness meditation, a practice of self regulating attention that lowers reactivity to stress triggers (Kabat - Zinn,1990). Mindfulness meditation helps to reduce physical symptoms of distress by balancing sympathetic and parasympathetic response. Practicing it regularly helps to inculcate positive emotions and thereby inducing mindfulness in everyday life. Thus it draws our attention to our daily routines. Hence it could be considered as a holistic approach that provides both mental and physical well being. This is actually an eight week program that takes about two and a half hours per week and includes a six hour daylong retreat between sixth and seventh weeks. Participants are asked to do practice it six days a week as homework and audiotapes are also given to aid it. MBSR by making use of stress reduction skills like meditation, hatha yoga , and a somatically focused technique known as body scan to teach participants how to pay attention in a particular way : which is on purpose, in the present moment and non judgmentally through this the practitioners become more mindful of their thoughts, emotions sensations and overall sense of self(Kabat - Zinn 1982). Some of the mindfulness technique used involves mindful breathing, mindful walking, mindful eating and mindful communication. In the efforts to explain therapeutic aspects of mindfulness studies have found out metacognitive awareness, decentering, reperceiving and decreased rumination are the theoretical aspects. Mindfulness-based cognitive therapy combines training in mindfulness meditation with cognitive therapy (Segal, Williams, \& Teasdale, 2002). Dialectical behavior therapy, an approach that has been shown to reduce self-mutilation and suicidal behavior in chronically suicidal patients with borderline personality disorder, provides training in mindfulness meditation to foster improvements in affect tolerance (Linehan, Armstrong, Saurez, Allmon, \& Heard, 1991). Acceptance and Commitment therapy it's an empirically based psychological intervention that combines the use of acceptance and mindfulness strategies along with commitment and behavior change strategies which aids in enhancing psychological flexibility.

\section{MINDFULNESS IN PANDEMIC SITUATION}

Spread of pandemic could totally turn the world upside down such an unexpected outbreak has floods the psychic atmosphere of human beings with anxiety, fear regarding its spread as well as the uncertainty concerning the lockdown period and its extension. Apprehensions of one's own health, health of our near and dear or the people whom we care about as well as a community as a whole. Due to the outbreak of such an infectious disease, it severely has an impact in mental health of individuals. As a result they may confront stress at varying degrees. This incorporates fear and worry about our health and our kith and kin, as we all are social beings under such situation we do feel suffocated moreover feels frustrated due to forced confinement within house for a long duration, feeling of isolation, stigmas and rumors spreading through medias could increase the feeling of fear since we care highly attentive or exhibit selective attention to all those stuffs related to pandemic. 
People's reaction to such a stressful situation may vary from person to person because of individual difference like personality traits are different, those with neurotic trait, extroverted, TYPE A personality individuals are more highly susceptible. Mental health issues that are likely to evolve are depression, Generalized anxiety disorders, OCD related to hygiene and cleanliness, marital problems, withdrawal symptoms in drunkards etc. To enhance the well being and quality of life of individuals the practices of above mentioned mindfulness exercises could be beneficial. Being mindful would guide us to become fully engaged in activities that we do I our daily life, thereby gives us a great capacity to cope with adverse events. By making it as a regular practice one could be able to focus on here and now experiences in addition enable them less likely to get mess up with worries about future or regret over past, also becomes less preoccupied with concerns about success and self esteem thereby help to form better deep connections with others. Mindfulness benefits are not only limited to psychological but also physical benefits like lowering blood pressure, tension, improves quality of sleep reduces chronic pain. Mindfulness meditation helps ones to accept their experiences (includes both positive and negative) by inculcating patience within us rather than reacting to them with aversion and avoidance. In short it supports us to come out of irrational, maladaptive and self defeating thought patterns.

\section{MINDFULNESS IN RELATION WITH PSYCHOLOGY AND PERSONAL GROWTH}

Basically mindfulness is related to the area of positive psychology. Founder of positive psychology Martin Seligman defined positive psychology as a scientific study of optimal human functioning that aims to discover and promote the factors that allow individuals and communities to thrive. it is an approach to study human thoughts, feelings and behaviour with a focus of strength instead of weakness. The connection between positive psychology and mindfulness are important when you consider the end results of mindfulness which is increased positivity, a greater sense of coherence better quality of life, more empathy, more satisfying relationships and more than everything greater hope (Wago \& Silbersweig, 2012). As stated by Richie Davidson, one of the world's most renowned contemplative neuroscientists, even 1. 5 hours of mindfulness practice can lead to positive structural changes in the brain i. e it could enhance neuroplasticity. Mindfulness practice seems to reduce stress, depression, anxiety, other mood disorders and thereby enhances activation in the regions of brain accountable for regulating attention and positive affective states which includes empathy, and other prosocial emotions also help in building resilience rather than getting into rumination. Many of the researches have shown that mindfulness has the capacity to boost working memory. The amygdala is a key stress-responding region in our brain and has a significant role in helping us cope with anxious situations. It's a well-known fact that high amygdala activity is associated with depression and anxiety disorders. A research has shown that long term mindfulness practices can actually reduce the size of amygdala, therefore it rises our stress reactivity threshold (Taren et al., 2013). It can also facilitate personal growth within individual. Mindfulness practice can contribute compassion and helps in eliminating burnout. Personal growth refers to the growth and enhancement of all aspects of the person the feelings the person has about himself or herself, and their effectiveness in living. It includes the development of positive life skills and the development of a realistic and healthy selfesteem. Personal development involves mental, physical, social, emotional, and spiritual growth that allows a person to live a productive and satisfying life within the customs and regulations of their society. it could help cultivate curiosity, perseverance. Regular as well as long term practice of mindfulness could contribute emotional regulation as emotion regulation is seen as one of the eminent aspect of personal growth. Mindfulness enables a person to effectively adapt to situations when stressed which could be denoted as self regulation also involves building effective coping skills.

Mindfulness is an important component of third wave behavioral therapies. Act - aware facet of mindfulness predicts depressive symptometology (Cash,M and Wittingham,K). In one of the studies 
conducted it has shown an empirical relationship between mindfulness and Carl Roger's concept of Self - actualization. Mindful self can help in self actualization through building self esteem. In reference to psychology mindfulness could be said as to some extent similar to metacognitive awareness. Metacognition enables us to reflect on our own thoughts it includes two clusters of activities: knowledge about cognition and regulation of cognition (Cross \& Paris, 1988; Flavell, 1979). Metacognitive knowledge refers to a person's knowledge or understanding of cognitive processes whereas metacognitive regulation refers to a person's ability to regulate cognitive processes during problem solving. Ones an individual indulge in mindfulness a reduction in emotional reactivity and avoidance behaviors could be seen which occur through a process of desensitization (Kabat Zinn,1981). Reperceiving is seen as the metamechanism that allows effective exposure to experiences (Shapiro,2006). Mindfulness have been proven beneficial for treating mood disorders, anxiety disorders, ADHD,eating disorders, various kinds of behavioral addictions. A cognitive restructuring occurs while we indulge in mindfulness practices. Initial findings also advocate that mindfulness has its applications in different branches of psychology like in organizational behaviour or occupational psychology it improves work related wellness, increase efficiency and productiveness hence leads to better job performance, in the field of forensic psychology it acts as a device for reducing reoffending, modulating impulsivity and thereby regulating anger, in school psychology for improving academic performance, knowledge acquisition, improves standards of mastering environment and cognitive functioning, in positive psychology it enhances optimism, compassion and well being, whereas in sport psychology it aids in achieving peak performance, situational cognizance and also allows to focus on task and in transpersonal psychology for improving non secular and meta cognitive attention(Shonin et al. , 2013).

Some of the mindfulness questionnaires are the Freiburg Mindfulness Inventory developed by
Bucheld, Grossman and Walach in 2001which consist of 30items to assess non judgemental, present moment observation and openness to negative experience, the Mindful Attention Awareness scale by Brown and Ryan in 2003 consist of 15 items used to measure attention to and awareness of present moment experience in daily life, Kentucky Inventory Of Mindfulness Skills by Bear, Smith and Allen in 2004 consist of 39 items measures 4 elements of mindfulness that are accepting present moment experiences without judgment, acting with awareness, describing , present moment experiences, the Cognitive and affective Mindfulness Scale Revised by Feldman et al in 2007 which consist of 12 items which measures attention, awareness, present focus, acceptance and non judgment of thoughts and feelings, the Five facet mindfulness Questionnaire by Baer et al in 2006 consist of 39 item composite of 5 instruments measures five elements that are observing, describing, acting with awareness, non judging of inner experience and non reactivity to inner experience others are the Philadelphia Mindfulness Scale, the Toronto Mindfulness scale etc.

\section{CONCLUSION}

Mindfulness enables optimal functioning in institutional, culture and global levels. Shapiro suggested that unfavorable effects were seen in three distinct domains that are intrapersonal (increased negativity, disorientation, boredom, addiction etc, interpersonal (family conflicts, more judgmental), and societal (increased alienation , discomfort with real world) and mindfulness practice yielded benefits in these areas. Through becoming mindful we know ourselves, where is our current state of mind, aware of what we do and other than that purpose behind everything, aware of how elements in environment interact with our being we domesticate a truer cognizance of ourselves, of others and of our environment. A regular practice of it can help us to live in the present as well as help us heal our psyche and body. Promotes to centre our mind and restore balance to our lives. 


\section{REFERENCES}

[1] Alidina, S., \& Marshall, J. J. Types Of Mindfulness Meditation. (n. d.). Retrieved from https://www.dummies.com/religion/spirituality/types-of-mindfulness-meditation/.

[2] Baer, R. (2011). Measuring Mindfulness. Contemporary Buddhism. 12(1) ,241-261.. https://doi.org/10.1080/14639947.2011.564842

[3] Beard, C. (2017). Mindfulness 101: Everything You Need To Know about Mindfulness. Retrieved from https://theblissfulmind.com/mindfulness-basics/

[4] Cash, M., \& Whittingham, K. (2010). What facets of mindfulness contribute to psychological well-being and depressive, anxious, and stress-related symptomatology? Mindfulness, 1, 177-182. https://doi.org/10.1007/s12671-010-0023-4

[5] Chapter II - Definition of The Term Sati And Sammasati. (n.d.). Retrieved from https://shodhganga.inflibnet.ac.in/bitstream/10603/203730/9/08 chapter2. pdf

[6] Cross, D. R., \& Paris, S. G. (1988). Developmental and instructional analyses of children's metacognition and reading comprehension. Journal of Educational Psychology, 80(2), 2131-142. https://doi.org/10.1037/0022$\underline{0663.80 .2 .131}$

[7] Davis, D. M., \& Hayes, J. A. (2012). What Are The Benefits of Mindfulness. American Psychological Association, 43(7), 64. Retrieved from https://www.apa.org/monitor/2012/07-08/ce-corner

[8] Hussain, D. (2015). Theoritical Analyses Meta cognition In Mindfulnes: A Conceptual Analysis. Psychological Thought. 8(2). https://doi.org/10.5964/psyct.v8i2.139

[9] Hyland, T. (2011). The Nature of Mindfulness. Retrieved From https://www.researchgate.net/publication/251412364_The_Nature_of_Mindfulness

[10] Kabat-Zinn, J. (1990). Full catastrophe living: Using the wisdom of your body and mind to face stress, pain, and illness. New York: Delacorte.

[11] Keng, S. L., Smoski, M. J., \& Robins, C. J. (2011). Effects of mindfulness on psychological health: A review of empirical studies. Clinical Psychology Review, 31(6), 1041-1056. https://doi.org/10.1016/j.cpr.2011.04.006

[12] Linehan, M. M., Armstrong, H. E., Suarez, A., Allman, D. \& Heard, H. L. (1991). Cognitive - behavioral treatment of chronically parasuicidal borderline patients. Archives of General Psychiatry, 48(12), 1060-1064. https://doi.org/10.1001/archpsyc.1991.01810360024003

[13] Marchand, W. R. (2014). Neural mechanisms of mindfulness and meditation: Evidence from neuroimaging studies. World Journal of Radiology, 6(7), 471-479. https://doi.org/10.4329/wjr.v6.i7.471

[14] Saeed, S. (2016). Origins of Mindfulness: Religion, Philosophy, or Psychology? Retrieved from http://mindfulspring.com/indian-origins-mindfulness/

[15] Satipatthana Sutta (n. d.). Retrieved from https://en.wikipedia.org/wiki/Satipatthana_Sutta

[16] Selva, J. (2020). History of Mindfulness: From East to West and Religion to Science. Retrieved from https://positivepsychology.com/history-of-mindfulness/

[17] Shapiro, S. L., Carlson, L. E., Astin, J. A., \& Freedman. B (2006). Mechanisms of mindfulness. Journal of Clinical Psychology, 62(3), 373-386. https://doi.org/10.1002/jclp.20237

[18] Shonin, E., Van Gordon, W., \& Griffiths, M. D. (2013). Mindfulness-based interventions: towards mindful clinical integration. Frontiers in psychology, 4, 194. https://doi.org/10.3389/fpsyg.2013.00194

[19] Taren A. A., Creswell J. D., \& Gianaros P. J. (2013). Dispositional mindfulness co-varies with smaller amygdala and caudate volumes in community adults. PLoS One, 8(5), e64574.

[20] Vago, D. R., \& Silbersweig, D. A. (2012). Self-awareness, self-regulation, and self-transcendence (S-ART): a framework for understanding the neurobiological mechanisms of mindfulness. Frontiers in human neuroscience, 6, 296. https://doi.org/10.3389/fnhum.2012.00296

[21] Segal, Z. V., Williams, J. M. G., \& Teasdale, J. D. (2002). Mindfulness-based cognitive therapy for depression: A new approach to preventing relapse. New York: Guilford Press, 3(2), 53-54. https://doi.org/10.1002/shi.90

Received on 10-12-2020

Accepted on 14-12-2020

Published on 23-12-2020

(C) 2020 Malavika S. P. and Subha Sachithanand; Licensee ATSK Publishers.

This is an open access article licensed under the terms of the Creative Commons Attribution Non-Commercial License (http://creativecommons.org/licenses/by-nc/3.0/) which permits unrestricted, noncommercial use, distribution and reproduction in any medium, provided the work is properly cited. 